\title{
DIREITO À JUSTIFICAÇÁO - DEVER DE JUSTIFICAÇÃO: REFLEXÓES SOBRE UM MODUS DE FUNDAMENTAÇÃO DOS DIREITOS HUMANOS ${ }^{1}$
}

\author{
Heiner F. Klemme ${ }^{2}$
}

\begin{abstract}
RESUMO: Neste texto, discute-se a concepção desenvolvida por Rainer Forst do "direito à justificaçãa", um princípio filosófico básico dos direitos humanos presente na tradiçâo da ideia kantiana de "razão pura prática”. Forst procura demonstrar que o reconhecimento do outro, como um ser finito e com necessidades, fundamenta diante de mim um direito a razóes justificadoras. A dignidade do outro me obriga a agir perante ele apenas conforme tais razóes, as quais ele pode compreender e aprovar. No texto, demonstram-se também alguns pontos fracos desse princípio de Forst que, sobretudo, resultam da insolúvel tensão entre uma teoria da razão prática e uma teoria do reconhecimento. Além disso, defende-se a tese de que o "direito à justificação" deve ser considerado "direito ao conhecimento do Bem” (Hegel), que a pessoa ativa tem em relação aos outros.
\end{abstract}

PALAVRAS-CHAVE: Direito à justificação. Rainer Forst. Direitos humanos. Razão prática.

Neste texto, pretendo discutir um princípio filosófico fundamental dos direitos humanos, que permite entendê-los como direitos válidos universal e categoricamente, sem ter em vista premissas metafísicas. Para tanto, o conceito de valor universal é esclarecido por meio do conceito de "razão pura prática", presente na tradição de Kant. Pode existir tal princípio fundamental em geral? O que se pensa com o conceito de valor aqui expresso? A diferença entre concepçóes políticas e filosóficas dos direitos humanos pode nos ajudar a esclarecer essas questóes.

\footnotetext{
${ }^{1}$ Palestra apresentada em Goiânia, na III Jornada de Filosofia e Direitos Humanos da Universidade Federal de Goiás, em setembro de 2007. Tradução de Clélia Aparecida Martins.

2 Professor da Johannes Gutenberg-Universität, em Mainz, Alemanha e diretor da KantForschungsstelle.
} 
Comecemos com o conceito político de direitos humanos, que, por seu lado, pode supor diversas expressóes. Primeiramente, pode-se falar de um conceito político ao se atribuir valor de um direito humano à formação jurídica efetiva da vontade do Estado. Aqui, valem os direitos humanos, porquanto eles constituem o direito estabelecido. Mas, em segundo lugar, "politicamente" também podem significar que os direitos básicos são fundamentados por um procedimento cujos resultados são aceitos pelos cidadãos, não obstante eles partirem de várias suposiçóes filosóficas, éticas ou religiosas. Esse procedimento medeia, por um lado, as convicçóes axiológicas contingentes - e, nesse ponto, incapazes de universalização dos cidadáos - e, por outro, a ideia de direitos fundamentais ou humanos universalmente válidos. Desde John Rawls, denomina-se construtivista esse princípio político fundamental.

Em contrapartida, em uma concepção (no estrito sentido da palavra) filosófica dos direitos humanos, fica clara a valorização de um direito humano exclusivo à existência de fundamentos, valores ou fatos <Tatsachen> de profundo valor, que descobrimos no momento de construirmos. Em regra, com uma concepção filosófica de direitos humanos, é levantada uma exigência moral que se esclarece pela referência à dignidade do homem, a sua existência como fim em si mesmo ou, ainda, a determinados interesses e necessidades universalmente compartilhados. Em uma concepção filosófica dos direitos humanos, a posição cognitivista-intuicionista a respeito deles acentua antes a dignidade e a responsabilidade de ser fim próprio de uma pessoa ou de nosso conhecimento de um sumo princípio normativo; por outro lado, para a posição empírico-antropológica a respeito dos direitos humanos, são centrais os interesses e as necessidades contrários. A seguir, nesta exposição, trato da posição cognitivista-intuicionista.

Como representar e defender essa concepção cognitivista-intuicionista dos direitos humanos? Como já exposto, na resposta a essa questão me ocupo com uma sugestão singular, a saber, com a concepção de Rainer Forst do direito à justificação. ${ }^{3}$ Tal concepção preenche ambas as condiçóes colocadas para uma versão moderna de uma concepção cognitivista-intuitiva de direitos

\footnotetext{
${ }^{3}$ Ver FORST, R. Praktische Vernunft und rechtfertigende Gründe. Zur Begründung der Moral. In: GOSEPATH, Stefan (Org.). Motive, Gründe, Zwecke. Theorien praktischer Rationalität. Frankfurt am Main: Suhrkamp, 1999a, p. 168-205; FORST, R. Das grundlegende Recht auf Rechtfertigung. $\mathrm{Zu}$ einer konstruktivistischen Konzeption von Menschenrechten. In: BRUNKHORST, Hauke et al. (Org.). Recht auf Menschenrecht. Menschenrechte, Demokratie und internationale Politik. Frankfurt am Main: Suhrkamp, 1999b, p. 66-105; FORST, R. Toleranz im Konflikt. Geschichte, Gehalt und Gegenwart eines umstrittenen Begriffs. Frankfurt am Main: Suhrkamp, 2003.
} 
humanos: com o direito à justificação, Forst obtém primeiramente o sentido incondicional e, por conseguinte, kantiano, do valor do núcleo moral dos direitos humanos, sem com isso precisar, em segundo lugar, retomar fortes suposiçóes metafísicas. Em vez disso, ele oferece a concepção de um direito à justificação no contexto da história da violação concreta dos direitos humanos e vincula-a a uma teoria intersubjetiva do reconhecimento.

Foquemos a concepção mais próxima do direito à justificação. Forst (1999b, p. 104) entende o direito à justificaçấo como um direito humano formal-abstrato, que é interpretado e definido em termos de conteúdo, no contexto de determinadas sociedades e de discursos político-sociais sobre a justiça, na forma de direitos humanos concretos. Ao contrário do direito à justificação, os direitos humanos concretos são reversíveis. Em contextos em mudança, eles podem e precisam ser reinterpretados. No entanto, a necessidade e a capacidade principal de revisão mantêm intacto o sentido de seu valor incondicional: como resultado da aplicação do direito à justificação, nos contextos particulares, os direitos humanos concretos podem se propagar com a pretensão de valor incondicional, porque a reserva falibilista contrária os atinge realmente in concreto, mas não in abstracto. Os direitos humanos concretos são resultados da aplicação de um procedimento definido por meio de bons fundamentos de discurso e contradiscurso, os quais tanto garantem a valorização incondicional de um direito humano, quanto levantam novos argumentos e tornam necessários seu exame e revisão em certos casos.

O direito à justificação, segundo Forst (2003, p. 590), deve-se a “[...] uma compreensão moral do princípio de justificação". Nesse sentido, todos os homens têm o direito fundamental de que pretensốes colocadas diante deles, ou a eles negadas, sejam justificadas com argumentos suficientes aos critérios de reciprocidade e de universalidade. Os homens oferecem razóes para suas açôes e são simultaneamente instruídos por fundamentações (FORST, 2003, p. 596). Em Forst, não está muito claro por que eles são instruídos por fundamentaçóes, todavia, suponho que isso decorra do fato de ele entender o princípio de justificação como um princípio da razão prática. Pensa-se com isso que as pessoas, na valorização do princípio de justificação, dispóem de um conhecimento racional e, por essa razão, também questionam os fundamentos 
da ação. Igualmente se esclarece sua disposição a conceder fundamentos por meio do conceito de razão prática. Por ser o princípio de justificação um princípio originário da razão prática, é que, para Forst, uma pessoa coloca a questão, quando ela mesma questiona as razões que justificam tal princípio. Desse modo, ela pergunta por qual razão se deve "respeitar" o outro "como 'fim em si mesmo', como ser com um direito à justificação" (FORST, 2003, p. 597). Para o respeito ao outro não há, porém, outras razóes:

Seu "ser homem" precisa ser suficiente para isso. Esse é um conhecimento de base moral, ao qual parte uma responsabilidade original perante os demais - e, em concomitância, também um conhecimento dos limites da fundamentaçáo moral, porque toda outra fundamentação do dever moral oriundo de fontes externas, sejam elas de natureza transcendental ou empírica, ameaça relativizar a moral. (FORST, 2003, p. 598).

Em outra citação, Forst refere-se ao conceito de conhecimento moral:

O conhecimento moral é assim essencialmente um conhecimento da responsabilidade defronte a outros, um conhecimento prático sobre o (recursivamente reconstruído) como e o incondicional que da justificação das ações moralmente mais relevantes conforme os critérios de reciprocidade e universalidade. A pre-tensão <An-spruch > à justificação concernente a outras pessoas vale para co-responder <ent-sprechen>, para responder a elas com razōes responsáveis. Sua "face" - para falar metaforicamente com Lévinas - é isso, exorta a percepção do dever à justificação - o dever que se "tem" como pessoa moral, isto é, como homem. ${ }^{4}$ (FORST, 1999a, p. 197-198).

Qual relação o reconhecimento do outro tem com o princípio de justificação? Enquanto Forst, em alguns lugares, escolhe formulaçóes que expressam o princípio de justificação como princípio básico da razão prática, como se fosse autoevidente, há outras formulaçóes que parecem colocar uma relação condicionante: por respeitarmos a dignidade do outro, devemos agir segundo razóes que bastam aos critérios de reciprocidade e de universalidade. Logo, aqui a tese do reconhecimento não esclarece o princípio de justificação, ao contrário, parece fundamentá-lo. A favor dessa versão estão as formulações nas quais Forst (2003, p. 597) alude a uma responsabilidade original perante outros como o "fundamento" da moral. O conhecimento da dignidade do

\footnotetext{
4 Em outra passagem, ele afirma que o "[...] dever incondicional de justificaçáo" não precisa ser entendido como "[...] pretensão negada ao outro [...] algo cujo cumprimento se deve ao outro, sem que para isso se necessite de acordo precedente" (2003, p. 598).
} 
outro é aqui a base da responsabilidade, e esta, novamente, a base do princípio de justificação: por que eu reconheço a dignidade do outro, devo expor-lhe as razões de minha ação. ${ }^{5}$

Entretanto, como o outro me obriga? Com base em sua finitude, expressa em sua vulnerabilidade e necessidade, o outro me obriga. Ao reconhecer essa finitude, eu atribuo ao outro dignidade. Por seu lado, esse conhecimento da razão prática fundamenta, conforme Forst, o princípio de justificação. Por fim, o princípio de justificação delineia o tipo e o modo por meio do qual eu respeito e reconheço o outro como fim próprio. De fato, Forst (2003, p. 597) acentua que não há "outras razôes" para o ato de reconhecimento, devido a aqui se tratar de um conhecimento da razão prática. Entrementes, não fica claro o que precisamente esse conhecimento diz. Em todo caso, com sua referência a Lévinas, Forst sugere antes uma versão não cognitivista do reconhecimento. Onde nisso deve estar a realização da razão prática? Por que em geral ela tem interesse na finitude de seres finitos e adjudica-lhes dignidade? Em função de o ato de reconhecimento não ser exatamente o ato mais racional, seria de esperar antes uma referência, por exemplo, a um sentido moral. Forst (2003, p. 596), porém, acentua expressamente que nós, no contexto moral, necessitamos tãosomente do conhecimento da razáo prática, mas não, por exemplo, de “[...] um sentido moral ou ainda de uma resolução ética”. A razão prática obriganos a sair de nós; a teoria do sentimento moral como o decisionismo ético, segundo Forst, apontam na direção falsa.

$\mathrm{O}$ ato de reconhecimento do outro deve ser compreendido mesmo como um conhecimento da razão prática; assim, a relação entre reconhecimento e princípio de justificação talvez possa ser também descrita do seguinte modo: a razão reconhece o princípio de justificação, o qual indica que todas as açóes perante pessoas finitas são justificáveis com argumentos. Esse dever geral por meio da razão prática corresponde a uma obrigação especial, que temos para com o outro concretamente, de reclamar fundamentos para nossas açóes. Sem o conhecimento racional do princípio de justificação, o outro não poderia nos obrigar - e sem o outro não teríamos razão para aplicar o princípio de justificação. Logo, ambos, o fundamento do dever e o princípio de justificação, estão baseados no conhecimento da razão prática. Expresso na terminologia

\footnotetext{
5 As pessoas veem, assim escreve Forst em uma passagem, que "estão" em um "[...] contexto original de responsabilidade [...], no qual elas se encontram sempre e que as obriga a se manterem como pessoas morais autônomas que podem agir responsavelmente, e verem realmente por meio de outros e não pela 'razão"” (FORST, 2003, p. 597).
} 
de Habermas, pode-se denominar isso como tese da "cooriginariedade" que possuem o reconhecimento e o princípio de justificação. Obviamente, essa tese leva a uma revisão importante da posição de Forst: enquanto ele valoriza muito a finitude do outro como a base de meu dever, segundo essa versão, meu dever de justificar minhas açóes perante o outro está assentado em um conhecimento direto da razão prática: como ser racional, tenho interesse nas formas racionais de interação, porque a razão prática é a parte mais integral de minha autocompreensão prática. Por isso, posteriormente também preciso levar esse "dever" aos seres que náo são mortais, e que mantêm o privilégio de poderem se mover livremente no espaço e no tempo. Em outras palavras: a razão obriga-me internamente; não me obrigo por meio da finitude do outro. Isso seria menos um dever e responsabilidade e mais a expressão de minha identidade e de minha autocompreensão normativa.

Vamos a um outro ponto: como sempre se pode esclarecer a relação entre reconhecimento e princípio de justificação, eis a razão, para Forst, de nos adjudicarmos mutuamente um direito à justificaçáo. Com isso, ele acentua continuamente nossa "responsabilidade original" para com o outro. Além disso, encontram-se ainda formulaçóes nas quais ele fala do reconhecimento do outro $e$ do meu mesmo como um "[...] ser finito, igualmente violável, justificador" (FORST, 2003, p. 597). Suponho que a evidência do outro se deve a sua précompreensão da moral, pelo que esta deve primariamente proteger interesses legítimos do outro. Logicamente, a argumentação considerada supôe uma teoria do direito à justificação, igualmente supóe a finitude do outro como do próprio eu. Em geral, apenas sob essa suposição pode ser compreensível como o outro é percebido como sujeito moral: quem propriamente não é sujeito moral, também não percebe o outro como sujeito moral. A percepção da própria dignidade não pode ser ordenada após a percepção da dignidade do outro. A percepção da finitude do outro, o reconhecimento exigido, inclui o reconhecimento da própria pessoa.

Como a razão prática reage a essa percepção? Conforme Forst, ela reage com o princípio de justificação; de acordo com isso, as causas são justificadas quando são suficientes aos critérios de reciprocidade e universalidade. Forst está seguramente correto: ambos os critérios apontados são expressão da razão prática. Mas não está claro por que a razão prática não pode ser interpretada no sentido do imperativo hipotético de Kant, como fundamento da prudência. Por que, a partir do reconhecimento do outro, segue o dever de ter colocado junto a ele um direito incondicional de justificação? Por que 
é concludente interpretar um princípio da razão prática como um princípio da - expresso na terminologia de Kant - razão pura prática, se ele também pode ser entendido sem problema como princípio da razão empírica prática? Por que é excluída uma compreensão do reconhecimento e da justificação, segundo a qual nós respeitamos o outro como "fim em si mesmo", porquanto ele, por seu lado, respeita-nos como fim em si mesmo? Como temos visto, Forst pensa que aquele que pergunta por que nós devemos considerar o outro como fim próprio coloca sempre uma questão. Sua responsabilidade como fim próprio <Selbstzweckhaftigkeit> nos parece evidentemente direta. Mas precisamente em razão de a questáo "por que devemos respeitar o outro?" poder ser respondida igualmente por meio da referência às causas da prudência, ela parece náo ser sem sentido: porque eu mesmo sou um ser finito, que pode ser ferido por outro, tenho uma boa razão para me unir a ele nas regras da vida em comum, regras úteis a ele e a mim simultaneamente. Destarte, se o outro me fere, como ser finito, náo tenho mais fundamento racional para tratá-lo como fim próprio. E me parece que Forst não oferece resposta satisfatória a essa objeção, a respeito da possibilidade de ser ferido pelo outro, o que me dá uma boa razão para abandonar o ponto central da justificaçáo universal e recíproca.

Voltemo-nos para a função do direito à justificação. Como visto, no entendimento de Forst, compete-nos reciprocamente um direito à justificação por causa da finitude de nossa natureza. Esse direito corresponde a um "dever incondicional", que não é confundido com a responsabilidade original (FORST, 2003, p. 597), a qual tem sido suficiente a nós e aos demais. Se agora, conforme Forst, essa responsabilidade original é o "ffundamento' da moral”, então evidentemente ela supóe o reconhecimento de um direito ou de um dever. Portanto, minha responsabilidade para com o outro precisa ter um fundamento que não pode ser idêntico ao direito, o qual, de acordo com ele, imputamo-nos apenas em decorrência dessa responsabilidade mútua. Esse fundamento está na dignidade do outro. O respeito pelo outro (e para consigo mesmo), bem como o conhecimento da razão prática na valorização do princípio de justificação, são primários, estão próximos da fala de um dever original, do qual me torno consciente tão logo percebo a "face" do outro. Nesse sentido, se o dever original de agir para com o outro segundo fundamentos recíprocos e universais está baseado no conhecimento de sua dignidade, por que devemos nos imputar adicionalmente, portanto, um direito fundador de justificação? Isso parece redundante. 
Essa objeção leva a uma outra problemática. Em geral, em uma teoria moral, tem sentido colocar o princípio de justificação no centro da concepção moral para discursar sobre direitos e deveres? $\mathrm{O}$ direito à justificação requer fundamentos que não podem ser refutados pelo outro de modo racional. Esses fundamentos instituem "normas - e correspondentemente modos de ação -, que possuem um caráter moral incondicional do dever e em sentido estrito são vinculadas categoricamente: como normas, de cujo valor - no mínimo prima facie - falam contra sem boas razóes" (FORST, 1999a, p. 178). Ou seja, tal direito requer fundamentos, cujo valor os que são contra o são sem boas razóes se o princípio de justificação mesmo gera esses fundamentos, não necessitamos nem de direitos conciliatórios, que precisamos imputar aos outros antes de essas razóes se tornarem boas razóes, nem de um dever que fundamenta. Se o princípio de justificação é um princípio da razão prática, necessita-se do caminho teórico valioso dos direitos e não dos deveres a eles correspondentes, para obter os fundamentos práticos que, como pensa Scanlon, ${ }^{6}$ não se pode rejeitar de modo racional. A boa fundamentação compromete-se sozinha com toda essa tarefa. O "direito a veto", que Forst atribui às pessoas em vista do direito à justificação que perderam, elas já possuem ante. As pessoas participam de uma práxis de discurso racional e de contradiscurso e com isso são motivadas intrinsecamente a querer oferecer razóes ao outro. E elas não necessitam para isso de desafio suplementar por meio de um outro. Se não fossem motivadas intrinsecamente, para querer agir conforme certos fundamentos que não podem rejeitar de modo racional, não seriam, por conseguinte, motivadas depois de terem se atribuído reciprocamente o direito à justificaçáo.

Enfim, neste texto, coloco-me contrário à concepção de Rainer Forst de direito à justificação. Para Forst, devido ao reconhecimento da finitude das outras pessoas, perante elas somos obrigados a justificar nossas açôes com argumentos. Com base em um conhecimento da razão prática, os outros têm defronte a nós o direito à justificação. Esse direito é um direito humano formal, seu conteúdo muda com os contextos concretos nos quais vivemos e agimos.

\footnotetext{
${ }^{6}$ Ver: SCANLON, T. M. What We Owe to Each Other. Cambridge, Mass.: Cambridge University
} Press, 2000. 
A concepção de Forst lembra um pouco a concepçáo de um neokantiano, Rudolf Stammler, exposta em seu texto Economia e direito segundo a interpretaçâo materialista da história ${ }^{7}$ (1906), sobre um direito natural de teor reciproco. Stammler esclarece-a com as seguintes palavras:

As velhas doutrinas do direito procederam injustamente táo logo perceberam um direito determinado de mais absoluto significado; mas elas teriam atuado de modo fundamentado se tivessem ambicionado um direito natural de teor reciproco: esses sáo princípios do direito que, dentre os procedimentos empiricos condicionados, contêm um direito teórico correto. Com isso, se apresenta a prova para a retidão teórica de um princípio do direito que avaliará criticamente e decidirá sobre quais princípios legais, sob relaçôes empiricamente dadas, são correspondentes aos fins últimos universalmente válidos da vida social. (STAMMLER, 1921, p. 174-175).

Contudo, a concepção de Forst ainda lembra naturalmente a interpretação de Hegel, pela qual as pessoas têm "direito ao conhecimento do Bem”. Cito os Princípios da filosofia do direito, de Hegel (1820/21):

$\mathrm{O}$ direito da vontade subjetiva consiste em que o que ela [vontade] reconhece como válido, deve ser por ela considerado bom, e que a ela uma ação, enquanto fim colocado na objetividade externa, conforme seu conhecimento dos valores dessas açôes nesta objetividade, é imputada justa ou injusta, boa ou má, legal ou ilegal. [...] O direito de não reconhecer o que nấo compreendo como racional, é o sumo direito do sujeito. ${ }^{8}$

Esse "direito ao conhecimento do Bem" não foi introduzido por Hegel no âmbito de uma teoria do reconhecimento. Diferentemente do "direito à justificação" de Forst, ele não está baseado no reconhecimento do outro como ser finito. Muito pelo contrário, trata-se de um direito que o homem que age e julga reivindica para si mesmo perante outros. Hegel, portanto, introduz o direito à justificação a partir da perspectiva da primeira pessoa: porque tenho um direito de conhecer o bem, posso não deixar determinar racionalmente meu querer por algo que não reconheço como bom e racional. Eu escolho de acordo com o conhecimento.

\footnotetext{
${ }^{7}$ STAMMLER, R. Wirtschaft und Recht nach der materialistischen Geschichtsauffassung. Leipzig 1906; citado segundo a quarta edição (de 1921, Berlin, Leipzig); ver também STAMMLER, R. Die Lehre vom richtigen Recht. Halle an der Saale 1926, Nachdruck Darmstadt: Wissenschaftliche Buchgesellschaft, 1964.

8 HEGEL, G. W. F. Werke in zwanzig Bänden, Bd. 7 (org. de E. Moldenhauer e K. M. Michel). Frankfurt a.M.: Suhrkamp, 1970, \$132, p. 245, 246.
} 
No sentido do direito racional moderno, de Locke a Rousseau até Kant, esse "direito ao conhecimento do Bem" pode ser bem concebido como o primeiro e mais original direito humano. Como sempre, podemos relacionar os aspectos singulares da explicação de Forst de um direito à justificação: essa posição alternativa de uma perspectiva cognitivista-intuicionista de fundamentação dos direitos humanos parece ser valiosa, no sentido de merecer respeito e ser discutida. Se, em uma teoria dos direitos humanos, queremos partir do conceito de razão pura prática, o direito humano original precisa ser desenvolvido a partir da perspectiva da primeira pessoa. Tão-somente o reconhecimento do outro não pode portar o peso da fundamentaçáo dos direitos humanos, porque o reconhecimento mesmo precisa estar baseado em fundamentos, os quais uma pessoa, que atua segundo eles, precisa poder reconhecer. O "direito ao conhecimento do Bem" supóe o reconhecimento do outro logicamente fundamentado.

KLEMME, Heiner F. Right to justification and duty of justification: reflections on a modus of the grounding of human rights. Trans/Form/Ação, Marília, v. 35, n. 2, p. 187198, Maio/Ago., 2012.

\begin{abstract}
This text discusses the conception developed by Rainer Forst of "right to justification", a basic philosophical principle of human rights present in the tradition of the Kantian idea of "pure practical reason". Forst aims to demonstrate that the recognition of the other, as a finite being and a being with needs, grounds before me a right to justifying reasons. The dignity of the other obliges me to act before him only according to such reasons, which he may comprehend and approve. The text also demonstrates some weak points of this principle of Forst that, above all, result in insoluble tensions between a theory of practical reason and a theory of recognition. Moreover, the thesis is defended that the "right to justification" must be considered a "right to recognition of Good" (Hegel) that the active person has in relation to others.
\end{abstract}

KEYWORDS: Right to justification. Rainer Forst. Human rights. Practical reason. 


\section{REFERÊNCIAS}

FORST, R. Praktische Vernunft und rechtfertigende Gründe. Zur Begründung der Moral. In: GOSEPATH, Stefan (Org.). Motive, Gründe, Zwecke. Theorien praktischer Rationalität. Frankfurt am Main: Suhrkamp, 1999a. p. 168-205.

Das grundlegende Recht auf Rechtfertigung. Zu einer konstruktivistischen Konzeption von Menschenrechten. In: BRUNKHORST, Hauke et al. (Org.). Recht auf Menschenrecht. Menschenrechte, Demokratie und internationale Politik. Frankfurt am Main: Suhrkamp, 1999b. p. 66-105.

Toleranz im Konfikt. Geschichte, Gehalt und Gegenwart eines umstrittenen Begriffs. Frankfurt am Main: Suhrkamp, 2003.

HEGEL, G. W. F. Werke in zwanzig Bänden. Bd. 7 (Org. de E. Moldenhauer e K. M. Michel). Frankfurt am Main: Suhrkamp, 1970.

SCANLON, T.M. What We Owe to Each Other. Cambridge, Mass.: Cambridge Univ. Press, 2000.

STAMMLER, R. Wirtschaft und Recht nach der materialistischen Geschichtsauffassung. Leipzig, 1906 (citado conforme a 4. ed. de 1921, Berlin; Leipzig).

. Die Lehre vom richtigen Recht. Halle an der Saale 1926, Nachdruck. Darmstadt: Wissenschaftliche Buchgesellschaft, 1964.

Recebido em: 02.01.2012

Aceito em: 18.02.2012 